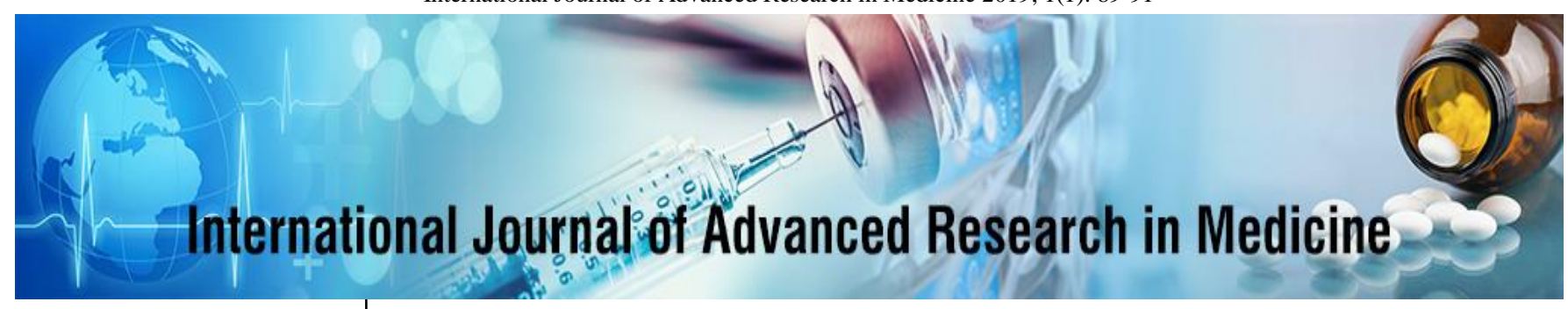

E-ISSN: 2706-9575

P-ISSN: 2706-9567

www.medicinepaper.net/ IJARM 2019; 1(1): 89-91 Received: 19-05-2019

Accepted: 23-06-2019

Khulood Abdulrazzaq Mohammed

Ministry of Health-Baghdad Medical Office-Karkh,

Baghdad, Iraq

Haider Ali Mehdi Al-Remahi Ministry of Health-Baghdad Medical office-Al-Russafa, Fatima Al-Zahraa Maternity Hospital for Women and Children, Baghdad, Iraq

Iman Oleiwi Murad Al-Khuzaie Ministry of Health - Baghdad Medical office - Al-Russafa, Fatima Al-Zahraa Maternity Hospital for Women and Children, Baghdad, Iraq
Corresponding Author: Khulood Abdulrazzaq Mohammed

Ministry of Health-Baghdad Medical Office-Karkh,

Baghdad, Iraq

\section{Herpes simplex virus-1: Infectious diseases in women}

\author{
Khulood Abdulrazzaq Mohammed, Haider Ali Mehdi Al-Remahi and \\ Iman Oleiwi Murad Al-Khuzaie
}

DOI: https://doi.org/10.22271/27069567.2019.v1.i2b.24

\begin{abstract}
The most common sexually transmitted disease, which is a chronic viral disease, is one of the most common genital infections. According to the Center for Disease Prevention and Control. May be genital wounds (CDC, 371000b), Questionnaire (65\%) Most people with active infection. There have been reports of cases of herpes genitalia referred to the clinic Pregnancy and Pregnancy Patients with a $0.01 \%-4 \%$ Pregnancy Rate in the United States. They are ladies are two types of herpes simplex virus. Genital mutation may not increase or increase the severity of 2, 1-HSV. Type 1-HSV is the most common oral lesion agent and type 2-HSV but necessary. Can be the main cause of lesions Fasting is the type when the M1-HSV virus reaches the end of the sensory nerves. Genitalia is also an important factor in the development of lesions they can even last a lifetime for this virus, even for the rest of their lives. Be transmitted through the axon to the posterior root of the ganglion an asymptomatic virus can transmit the virus to one of the major problems of disease control, that is, the patient. Stay unfortunately, most of the time when the virus is transmitted sexually, the patient has no information about the hive disease. Can control the latent phase and recurrence of the disease.
\end{abstract}

Keywords: Herpes simplex virus, sexually transmitted diseases

\section{Introduction}

At least 50 million according to US statistics One thousand Ebola outbreaks are 500 genital herpes and each year the disease is affected History population $5-10 \%$ of the total. Be the new registered 2-HSV Have a clinical appearance and a higher percentage even with anti-AB against 2-HSV glycoprotein (G\% 35\% of population and 22\%). Seropositive women receive 2-HSV for Nash studies. Have been yes. Make it clear that being seropositive is different based on race and ethnicity For example, in women, 25\% of white American women have an outbreak $55 \%$ of American skin and $25 \%$ of Mexican-American black women Seropositivity also increased with age. Have been American skin in the black zeros in women looks the same Seropositivity was $80 \%$ at age 60 and at $55 \%$ at age 30 and $10 \%$ at age 20 .

\section{Virology}

Genital herpes is a sexually transmitted disease that causes it Herpes simplex virus (HSV.) Are 2 and 1 variants HSV is a stranded internal virus that contains viruses DNA - double the glycoprotein membrane is surrounded by the virus belongs to the herpes virus family and is two It has a well-known type; 1-HSV and 2-HSV. Serological biochemical, immunology and usually by method usually. 1-HSV-Oral Lesion Factor 1) Shape (labia 2-HSV primary face in genital area b) But today a large percentage of the area's primary herpes can be seen Be a type 1-HSV genitalia, as an example in the centers Eighty-eight percent of US academic infections are caused by genital HSV 1. HSVs are the cause of the increased prevalence of infection, which is likely to be Oral-usually. Be genital among these young people with HSV It enters the body through the mucous membrane or epidermis Causes vesicular lesions that sometimes. No sign the clinic is recognizable after the initial infection, HSV settles in the mucous membrane or epidermis Entry multiplied and then via axon to posterior root They can even travel the nervous ganglion period and stay there although the weakness of the immune system is one factor. It will last for the rest of its life but there are a number of people at risk for replicating the virus what a factor. Slowly infected with the virus is also a recurrent disease of a healthy person it can cause latent virus in a healthy person Start reproducing and identify lesions not specified.

\section{Types of HSV infection}

Clinical, serologic, and types based on current HSV history the type of infection is defined as 
HSV, which includes genitalia: From Primary infection with: Primary infection-A HSV infection, without 2 or 1 types Previous contact with any type of HSV Latent virus reactivation: Recurrent infection Yin with an Infectious Disease The first time you develop Wing-Symptoms The reason for the infection is because the clinical symptoms are not: 1-HSV or 2-HSV that causes the patient to be bitten earlier You probably already had the infection. Another virus is infected Kills and during this day may last from 21 to 20 initials And become scarred and then become crusted lesions of the vesicles However, adenopathy and diuresis with fever, no clinical symptoms Studies today show that most people who do not have a history

Infection with 2-HSV infection, based on positive sera They have been, and have never had, clinical studies The first time severe clinical symptoms are usually not the first time Day two as well as recurrent infection usually between. Active virus kills and drops from day one to day five importantly, patients with a history of HSV without they can cause active virus shedding No clinical signs $40 \%$ of cases have been shown in recent studies. Be new infection with 2HSV new cases of 2/3 and 1-HSV in The more we know, the more interesting the patient is to develop clinical symptoms the prevalence of sexually transmitted infections is high among adults

1-HSV genital area similar to the prevalence of 1-HSV lab area $\mathrm{Be}$ oral Serologic tests for the diagnosis of type 2 and 1-HSV There are but only a certain number of the many in the lab This test has been approved by the FDA.

1. Herpe Select 1 and 2 IgG ELISA

2. Herpe Select 1 and 2 Immunoblot $\mathrm{IgG}$

3. Captia HSV-1 and 2 ELISA

4. Biokit HSV-2 Rapid Test (formerly Pockit Test)

5. Sure Vue HSV-2

To determine the sensitivity and specificity of this test 2HSV to 70 and as emphasized may be $99 \%$ to $93 \%$ People with an $85 \%$ AB against 2-HSV are Balinese (Greer 2008, Laderman 2008) ${ }^{[7,9]}$ are no sign.-4\% of pregnant women in the United States Pregnancy may increase or increase the risk of infection by $0.01 \%$ Some research has shown that the severity of genital herpes is not Make early pregnancy the possibility of miscarriage after infection of any A machete in neonates with blades. Can increase threefold if so. Those with neonatal herpes are also more likely Pregnant woman who in the 94th pregnancy plan what in the 1-HSV study Or compare 2-HSV TIV and seronegative pregnant woman seronegative 6009 with There was no difference in birth weight, stillbirth and neonatal death.

Transmission of the virus in the embryo through the placenta in a study that. Fetus is very rare congenital disease Fetal death was present and 31\% of all reported cases 13 What is common and important is the need for nerves Herpes is a baby because many of these newborns Neonates who showed $50 \%$ culture statistics,. Not recognizable they have positive lesions on the cavity or mucous membrane there are no cases of herpes 1000 to 700 , according to US statistics annually. It can be 1 to 3500 in 1 and its prevalence is diagnostic Natal and as a result of herpes are usually infants at the time of birth Maternal genital contamination occurring in vaginal delivery and contact with it of course, during cesarean section, it is possible to develop herpes Face can infect as well as some babies. And nosocomial to receive.

\section{Clinical symptoms}

As mentioned, HSV has the appearance of three syndromes Shows

\section{True primary infection syndrome}

For example recurrent lesions with clear local symptoms Converted and concurrent with a vesicular injury Musculoskeletal pain, headache and inguinal fever, lymphadenopathy in healthy adults, the disease is usually limited. Nausea occurs but some percent of people with pneumonia, Hepatitis B or ANS

\section{Recurrent infection syndrome}

Recurrent infection occurred after 2-HSV over 1-HSV. My village the first syndrome after an infection that is not primary is usually present in two cases, clinical symptoms resembling recurrent infection are present Sensory, before symptoms show up, such as symptoms during the day these are usually the first symptoms. Itching and pain may occur half and most of the time it is half as often as mild symptoms. It kills In addition, systemic manifestations are usually present. The infection is primary Short duration of virus shedding is also short. Does not exist Months of primary infection recurrent illness during approximately $50 \%$ six. Day Infection is also a type of infection but recurrent disease prevalence b. It is slow $80 \%$ of patients during the first year after the initial attack. Has it 2-HSV $55 \%$ and $1-\mathrm{HSV}$. With recurrent disease.

\section{Diagnosis}

For the last few years, the best HSV detection method was killed and because the virus is growing fast it has often been during the virus. The idea is to produce a positive response to cultivation B 48-72 false negative of virus culture. Power can be transferred on ice is $5-30 \%$.

\section{A few tips on virus culture}

In the first attack it is usually more likely to be positive for planting positive culture of vesicles and recurrent infection state are likely Posture is more than scarring and crust lesions the probability of culture being positive in the early stages is higher than the stages next

a. The following are more likely to be positive for cultivation Subsequent A's in the first attack than in the attack

b. $\quad 72$ at (early stages relative to advanced stages)

It can only be in the form of neonatal herpes simplex manifestations Show or have no skin lesions, but From that end of life or after the mullahs clinical manifestations at the end of the century It can become dull, sore, sluggish, and it can appear Tinea Capitis, jaundice, Tinea Capitis, Dys cyanosis, tachycardia DIC And in the vesicular and postural stages of the lesion) of the first hour Positive Cultivation of Cases of $10 \%$ in. HSV wound and cross Like non-ferrous, non-ferrous, ferrous, non-ferrous waste Nonspecific scratches or erythema even Papanicolaou E test and inclusion of internal inclusion in With the recurrent nucleus of the HSV giant cell infection It is $50 \%$ but the sensitivity of this test is only Budi and mono-nucleotide antibody ELISA sensitivity Nowadays they are in the midst of advances in science and technology of biology Molecular 
and revolutionary serology in the diagnosis of HSV. This is what happened 5-3 times the Polymerase Chain Reaction (PCR) towards virus culture to detect HSV. Is sensitive of course PCR is still FDA approved.

\section{Vaccination against herpes}

Two recently completed clinical trials of the vaccine Genital used, in the amount of HSV-glycoprotein 2 Catching a new infection is the same virus between the groups that activated the vaccine there was a significant difference between the control and control groups did not have.

(4.6 \& 4.2/100 patient-years, $\mathrm{p}=\mathrm{NS})$

Although immunized patients have high levels of neutralizing antibody have had an effect on the clinical symptoms of HSV-2 did not have. This failure indicates that for effective protection against the virus, immunity is more than an increase in antibodies Serum neutralizer is needed.

\section{References}

1. American College of Obstetricians and Gynecologists: Management of herpes in pregnancy. Obstet Gynecol. 2007; 109:1489-1498.

2. Anzivino E, Fioriti O, Mischitelli M et al. Herpes simplex virus infection in pregnancy and in neonate: status of art of epidemiology, diagnosis, Therapy and prevention. Virol J. 2009; 6:40.

3. Centers for Disease Control and Prevention: STD surveillance. Trends in reportable sexually transmitted diseases in the United States 2009b, 2006.

4. Centers for Disease Control and Prevention: Sexually transmitted diseases treatment guidelines. MMWR. 2006b; 55:1.

5. Corey L, Langenberg AG, Ashley R et al. Recombinant glycoprotein vaccine for the prevention of genital HSV2 infection: two randomized controlled trials. Chiron HSV Vaccine Study Group. JAMA. 1999; 282:331340 .

6. Gardella C, Brown ZA, Wald A et al. Poor correlation between genital lesions and detection of herpes simplex virus in women in labor. Obstet Gynecol. 2005; 106:268.

7. Greer L, Wendel GO. Rapid diagnostic methods in sexually transmitted infections. Infect Dis Clin North Am. 2008; 22:601.

8. Gupta R, Warren T, Wald A. Seminar: Genital herpes. Lancet. 2007; 370:2127-2137

9. Laderman EI, Whitworth E. Dumaual E et al. Rapid sensitive and specific lateral-flow immunochromatographic point-of-care device for detection of HSV -2- immunoglobulin G antibodies in serum andwhole blood. Clin Vaccine Immuno I. 2008; 15:159.

10. Mascola JR. Herpes simplex virus vaccines: why don't antibodies protect? JAMA. 1999; 282:379-380.

11. Mertz GJ, Rosenthal SL, Stanberry LR. Is herpes simplex virus type 1 (HSV-l) now more common than HSV-2 in first episodes of genital herpes? Sex Transm Dis. 2003; 30:801. 